$$
\begin{aligned}
& \text { RECEIVED CONF-9703100--1 } \\
& \text { JUI } 701997 \\
& \text { OSTI }
\end{aligned}
$$

\title{
ENTRAINMENT MEASUREMENTS IN ANNULAR FLOW
}

\author{
A. Assad, C. Jan and M. de Bertodano \\ Purdue University \\ S. G. Beus \\ Westinghouse Electric Corporation
}

\author{
DE-AC11-93PN38195
}

\begin{abstract}
This report was prepared as an account of work sponsored by the United States Government. Nelther the United States, nor the United States Department of Energy, nor any of their employees, nor any of their contractors, subcontractors, or their employees, makes any warranty, express or implied, or assumes any legal liability or responsibility for the accuracy, completeness or usefulness of any Information, apparatus, product or process disclosed, or represents that its use would not infringe privately owned rights.
\end{abstract}

Operated for the U.S. Department of Energy by WESTINGHOUSE ELECTRIC CORPORATION 


\section{DISCLAMMER}

Portions of this document may be illegible in electronic image products. Images are produced from the best available original document. 


\title{
Entrainment Measurements in Annular Flow
}

\author{
A. Assad, C. Jan and M. de Bertodano \\ Purdue University \\ Thermo-Hydraulics and Reactor Safety Laboratory \\ West Lafayette, IN 47907-1290 \\ and \\ Stephen Beus \\ Bettis Atomic Power Laboratory \\ Westinghouse Electric Corporation \\ West Mifflin, PA 15122-0079
}

\begin{abstract}
Air/water and vapor /freon were utilized to scale and simulate annular two-phase flow for high pressure steam/water conditions. A unique vapor/liquid Freon loop was built to obtain the high pressure data. The results were compared with two correlations available in the open literature. The Ishii and Mishima dimensionless group was able to scale the data remarkably well even for vapor/liquid Freon. However the correlation needs to be adjusted for high Weber numbers of the gas phase.
\end{abstract}

\section{Introduction}

The droplet entrainment in annular gas/liquid flow is the fraction of the liquid flow that is dispersed in the gas core. The rest flows in a liquid film along the wall.

There are two widely used techniques to measure the entrainment fraction. One is to measure the droplet flow directly using isokinetic probes. The second is to extract the liquid film through a porous probe or some equivalent arrangement. This last technique is probably more accurate because it is difficult to obtain a measurement of the droplet flow near the film.

Most of the data available has been obtained in air/water experiments at atmospheric pressure. However many applications operate under very different conditions. For the case of high pressure steam boilers the density ratio and the surface tension are quite different from these experiments.

The available correlations must rely on these data and therefore there is some uncertainty when they are applied to other situations. The present experiments employ air/water and Freon-113 data with the objective to bridge this gap in experimental data.

\section{Previous work}

\subsection{Available data.}

We have selected two representative data sets from the open literature: The low pressure air/water data of Cousins and Hewitt (1968) and the high pressure steam/water data of Keeys et. al. (1970). For the first set, the entrainment fraction is below $40 \%$ and for the second it is above $70 \%$. Therefore there is a gap in the middle. Furthermore whereas the first set is one of many available in the open literature, the second is unique.

Cousins and Hewitt's (1968) experiments were carried out in adiabatic, upwards, air/water flows in tubes at near ambient temperature and low pressure, i.e. 0.14 to $0.24 \mathrm{MPa}$. A $9.5 \mathrm{~mm}$ (3/8 in) I.D. bore acrylic resin tube and a $31.8 \mathrm{~mm}$ ( $11 / 4 \mathrm{in}$ ) I.D. bore copper tube were employed. The tube lengths used to attain equilibrium conditions are 2.2 $\mathrm{m}$ (7.17 ft.) for acrylic resin and $9.8 \mathrm{~m}$ (32 ft) for copper, respectively.

The distance necessary to reach an equilibrium condition is given by Kataoka and Ishii (1982) as follows;

$$
Z \approx 440 D W e_{l}^{0.25} / \operatorname{Re}_{f}^{0.5}
$$

where,

$$
W e_{l} \equiv \frac{\rho_{g} j_{\delta}^{2} D}{\sigma}\left(\frac{\Delta \rho}{\rho_{g}}\right)^{1 / 3}
$$

and

$$
\operatorname{Re}_{f} \equiv \frac{\rho_{f} j_{f} D}{\mu_{f}}
$$


For Cousins and Hewitt's experiments, the value of $440 \mathrm{We}^{0.25} / \mathrm{Re}_{\mathrm{f}}{ }^{0.5}$ lies between 50 and 150 . Hence, the entrainment fractions measured at the tube exit can be regarded as the equilibrium value, since $Z / D$ is greater than 230 at this point for all cases.

As shown in Figure 1, the injected liquid film was removed by suction through a porous wall section (S1) and the liquid film formed by redepositing droplets was removed by suction through porous wall (S2). The flow rate of entrained liquid $\left(W_{L E}\right)_{1}$, was determined by a mass balance equation:

$$
W_{L}=\left(W_{L F}\right)_{1}+\left(W_{L E}\right)_{1}
$$

Here, $W_{L}$ is the inlet liquid flow rate, $\left(W_{L F}\right)_{1}$ is the liquid film removal rate though porous wall section (S1).

The importance of this experiment is that the deposition rate is also measured with the second suction probe. Various deposition lengths were measured.

Keeys et al. (1970), measured the liquid entrainment in adiabatic annular steam/water flows at high pressures (3.447 and 6.894 MPa). The 12.6 $\mathrm{mm}$ I.D. test section was $3.66 \mathrm{~m}$ long. The value of $440 \mathrm{We}_{\mathrm{l}}{ }^{0.25} / \mathrm{Re}_{\mathrm{f}}{ }^{0.5}$ lies between 10 to 27 and $\mathrm{Z} / \mathrm{D}$ is 290. This ensures equilibrium conditions at the liquid film extraction point. As shown in Figure 2, the liquid film flow rate is measured by extracting the film through a film removal device at the end of the test section. The steam, which is inevitably removed with the liquid film, is passed into a trace-heated cylinder and pumped back through another orifice 'O2'. When the pressure difference across orifice 'O2' is increased, the liquid film removal rate increases until a plateau is reached. The true liquid film flow rate was taken as this value.

\subsection{Available correlations}

Several correlations have been developed. Some of these correlations have been reviewed by Ishii and Mishima (1989). Two representative correlations are shown below: Dalman et. al. (1979) and Ishii and Mishima (1989).

Ishii and Mishima (1989) proposed a detailed correlation on the basis of an entrainment inception criterion and a force balance at the wavy interface as follows:

$$
E_{\mathrm{cos}}=\tanh \left(7.25 \times 10^{-7} W e_{I}^{1.25} \operatorname{Re}_{f}^{0.25}\right)
$$

where $W e_{1}$ is defined in Equation (2).

This correlation indicates that the equilibrium entrainment fraction $E_{\infty}$ depends on the total liquid Reynolds and gas Weber numbers.

Dallman et al. (1979) correlated the entrainment rate from a liquid film as:

$$
\dot{\varepsilon}=k_{A}\left(\frac{W_{L F}-W_{L F C}}{P}\right) u_{g}^{2} \rho_{g}^{1 / 2} \rho_{f}^{1 / 2}
$$

where $k_{\mathrm{A}}$ is an entrainment coefficient, $P$ is the perimeter of the wetted surface and $W_{L F C}$ is the critical liquid mass flow rate required for the onset of entrainment. For air/water upflow $k_{A}=3.5 \times 10^{-6}$ $\sec ^{2} / \mathrm{kg}$ and $W_{\mathrm{LFC}} / P=0.046 \mathrm{~kg} / \mathrm{m} \mathrm{s}$.

The deposition rate is represented in terms of the concentration of droplets in the gas core, $\mathrm{C}$, and the deposition coefficient, $k_{D}(\mathrm{~m} / \mathrm{sec})$, as:

$$
\dot{d}=k_{D} C \equiv k_{D} \frac{\rho_{g} W_{L E}}{W_{G}}
$$

At steady state, the rate of deposition from the gas core is equal to the entrainment rate from the liquid film, ie.,

$$
\dot{d}=\dot{\varepsilon}
$$

Inserting equations (6) and (7) into equation (8), Dallman obtained:

$$
\frac{E}{E_{M}}=\frac{\frac{k_{A} \sigma j_{g}}{4 k_{D}} W e_{D}}{1+\frac{\sigma j_{g}}{4 k_{D}} W e_{D}}
$$

where we have defined:

$$
W e_{D}=\frac{\rho_{g} j_{g}^{2} D}{\sigma} \sqrt{\frac{\rho_{f}}{\rho_{g}}} \text { and } E_{M}=1-\frac{W_{L F C}}{W_{L}}
$$

Since equations (5) and (10) were developed using a limited set of experimental data in low pressure air/water flows, it is expected that the correlations may not apply directly to high pressure situations. 


\section{Scaling}

The current experiments were designed to simulate steam/water flow at 13.6 MPa in a small diameter tube.

The difficulty with scaling the interfacial phenomena in annular two-phase flow is that they are not well understood. The state-of-the-art correlations are empirical. We have chosen the best known dimensionless correlations in the hope that the dimensionless numbers that form them are sufficient to scale the interfacial mechanisms.

The entrainment rate correlation of Kataoka and Ishii (1982) was derived based on the correlation by Ishii and Mishima (1989). For fully developed annular flow they obtained:

$$
\frac{\dot{\varepsilon D}}{\mu_{f}}=6.6 \times 10^{-7} \operatorname{Re}_{t f}^{0.185} W e_{f}^{0.925}\left(\frac{\mu_{z}}{\mu_{f}}\right)^{0.26}
$$

where $R e_{\mid f}=R e_{1}(1-E)$. Combining equations (11) and (5) we obtain:

$$
\frac{\dot{\varepsilon} D}{\mu_{f}}=\phi\left(W e_{g}, \operatorname{Re}_{l}, \frac{\rho_{\mathrm{f}}}{\rho_{\mathrm{g}}}, \frac{\mu_{f}}{\mu_{g}}\right)
$$

The interfacial shear correlation of Wallis (1969) is based on the premise that the interfacial roughness is proportional to the film thickness:

$$
c_{f_{i}}=0.005\left(1+300 \frac{h}{D}\right)
$$

Henstock and Hanratty (1976) used the approach that the flow in the film is similar to singlephase flow. The film was assumed to be uniform and the mixing length model was used to caloulate the liquid velocity to obtain:

$$
\frac{h}{D}=\frac{6.59 F}{\sqrt{1+1400 F}} \text { where } F=\frac{\gamma\left(\operatorname{Re}_{l f}\right)}{\operatorname{Re}_{g}^{0,9}} \frac{\mu_{f}}{\mu_{g}} \sqrt{\frac{\rho_{g}}{\rho_{f}}}
$$

and $\gamma\left(R e_{\mid f}\right)$ is an algebraic function.

By a similar argument as used for equations (12) it follows that:

$$
c_{\pi}=\psi\left(W e_{g}, \operatorname{Re}_{l}, \operatorname{Re}_{g}, \frac{\rho_{\mathrm{f}}}{\rho_{\mathrm{g}}}, \frac{\mu_{f}}{\mu_{g}}\right)
$$

Equation (15) has one more dimensionless group than equation (12), $\mathrm{Re}_{\mathrm{g}}$.

To obtain similarity the five dimensionless groups on the RHS of equation (15) should be the same. Table 1 is a comparison between a steam/ water reference case and six experimental cases. The hydraulic diameter is $6 \mathrm{~mm}$ for the reference case and $10 \mathrm{~mm}$ for the experiments. Freon-113 and air/water are used in this analysis.

The velocities, $j_{l}$ and $j_{g}$, are chosen such that $R e_{1}$ and $W e_{g}$ are similar. The only other variable that is controlled is the pressure.

The Reynolds number for the gas phase, $R e_{g}$, turns out to be within a factor of two of the reference value for all cases. However the density ratio and the viscosity ratio vary greatly. The closest values are obtained with Freon-113 at $2 \mathrm{MPa}$ and in fact they are quite close. On the other extreme air/water at $0.5 \mathrm{MPa}$ exhibits values which are more than one order of magnitude greater than the reference case. Furthermore the gas velocity at this condition is very high, beyond practical limits.

There is one further advantage with Freon-113, that the surface tension is very low. In fact it is smaller than the reference condition. This is important in case that some significant dimensionless group was missed.

Table 1 Annular Flow Scaling.

\begin{tabular}{|l|c|c|c|c|c|c|c|c|c|}
\hline Fluids & $\mathrm{P}$ & $\mathrm{T}$ & $\mathrm{j}_{\mathrm{l}}$ & $\mathrm{j}_{\mathrm{g}}$ & $\mathrm{Re}_{\mathrm{l}}$ & $\mathrm{Re}_{\mathrm{g}}$ & $\mathrm{We}_{\mathrm{g}}$ & $\rho_{\mathrm{I}} \rho_{\mathrm{g}}$ & $\mu_{\mathrm{f}} / \mu_{\mathrm{g}}$ \\
\hline \hline $\begin{array}{l}\text { Steam/ } \\
\text { Water }\end{array}$ & 13.6 & 334 & 0.5 & 20 & $\begin{array}{c}2.3 \\
\mathrm{E}+4\end{array}$ & $\begin{array}{c}4.8 \\
\mathrm{E}+5\end{array}$ & $\begin{array}{c}1.4 \\
\mathrm{E}+4\end{array}$ & 7.5 & 3.92 \\
\hline $\begin{array}{l}\text { Freon } \\
(113)\end{array}$ & 2 & 180 & 0.357 & 7.347 & $\begin{array}{c}2.3 \\
\mathrm{E}+4\end{array}$ & $\begin{array}{c}7.3 \\
\mathrm{E}+5\end{array}$ & $\begin{array}{c}1.4 \\
\mathrm{E}+4\end{array}$ & 7.1 & 10.92 \\
\hline $\begin{array}{l}\text { Freon } \\
(113)\end{array}$ & 1 & 140 & 0.426 & 15.95 & $\begin{array}{c}2.3 \\
\mathrm{E}+4\end{array}$ & $\begin{array}{c}7.3 \\
\mathrm{E}+5\end{array}$ & $\begin{array}{c}1.4 \\
\mathrm{E}+4\end{array}$ & 19.3 & 16.23 \\
\hline $\begin{array}{l}\text { Freon } \\
(113)\end{array}$ & 0.5 & 100 & 0.503 & 27.49 & $\begin{array}{c}2.3 \\
\mathrm{E}+4\end{array}$ & $\begin{array}{c}7.3 \\
\mathrm{E}+5\end{array}$ & $\begin{array}{c}1.4 \\
\mathrm{E}+4\end{array}$ & 40.9 & 23.65 \\
\hline $\begin{array}{l}\text { Air/ } \\
\text { Water }\end{array}$ & 2 & 20 & 2.327 & 84.47 & $\begin{array}{c}2.3 \\
\mathrm{E}+4\end{array}$ & $\begin{array}{c}1.0 \\
\mathrm{E}+6\end{array}$ & $\begin{array}{c}1.4 \\
\mathrm{E}+4\end{array}$ & 42.4 & 52.63 \\
\hline $\begin{array}{l}\text { Air/ } \\
\text { Water }\end{array}$ & 1 & 20 & 2.327 & 119.5 & $\begin{array}{c}2.3 \\
\mathrm{E}+4\end{array}$ & $\begin{array}{c}7.4 \\
\mathrm{E}+5\end{array}$ & $\begin{array}{c}1.4 \\
\mathrm{E}+4\end{array}$ & 84.7 & 52.63 \\
\hline $\begin{array}{l}\text { Air/ } \\
\text { Water }\end{array}$ & 0.5 & 20 & 2.327 & 168.9 & $\begin{array}{c}2.3 \\
\mathrm{E}+4\end{array}$ & $\begin{array}{c}5.2 \\
\mathrm{E}+5\end{array}$ & $\begin{array}{c}1.4 \\
\mathrm{E}+4\end{array}$ & 169.5 & 52.63 \\
\hline
\end{tabular}




\section{Experiments}

\subsection{Air/Water experiment.}

The experimental loop utilized is similar to Cousin and Hewitt's (1968). One of the main objectives of the present work is to extend the range of their data to higher flows and pressures.

There are 121 experimental data points. The range of experimental data was extended on both air and water flows. The range of $\rho_{f} j_{f}^{2}$ is 5.5 to 289 $\mathrm{kg} / \mathrm{ms}^{2}$ and the range of $\rho_{\mathrm{g}} \mathrm{jg}^{2}$ is 480 to $45000 \mathrm{~kg} /$ $\mathrm{ms}^{2}$ (see Figure 3 ). The experiments were conducted at four different pressures. All measurement ranges are listed in Table 2.

Table 2 Range of parameters.

\begin{tabular}{|c|c|c|}
\hline Parameter & Unit & Range \\
\hline \hline Air flow & $\mathrm{kg} / \mathrm{sec}$ & $0.0028-0.028$ \\
\hline Water flow & $\mathrm{kg} / \mathrm{sec}$ & $0.0053-0.038$ \\
\hline $\mathrm{j}_{\mathrm{f}}$ & $\mathrm{m} / \mathrm{sec}$ & $0.074-0.54$ \\
\hline $\mathrm{j}_{\mathrm{g}}$ & $\mathrm{m} / \mathrm{sec}$ & $24.5-126$ \\
\hline Pressure & $\mathrm{kPa}$ & $140-240-380-660$ \\
\hline
\end{tabular}

\subsection{Entrainment measurement (air/water).}

The water injected into the test section forms a liquid film around the periphery of the tube. As the liquid film flows up the tube, part of the liquid film is entrained as fine droplets in the gas core. When fully developed flow is established the entrainment rate is equal to the deposition rate and the entrainment fraction reaches its asymptotic value. Since the length between the top of the mixer to the inlet of the first extraction unit is about 440 diameters, fully developed annular flow is expected.

The entrainment fraction, E, can be calculated from the following expression:

$$
E=1-\frac{W_{L F 1}}{W_{L}}
$$

To monitor the liquid film extraction, the flow immediately downstream of the extraction probe was observed. When the extracted air flow was increased, the liquid film downstream of the extraction unit decreased. When the extracted air flow increased further, a dramatic change of the flow regime in the visualization section was seen. The tube turned from opaque to transparent. After that, no matter how much more air flow was extracted, no difference of the flow regime was observed. It was assumed that the liquid was extracted completely at that point.

But for high water flows, it was hard to tell when the liquid film was extracted completely by visualization. A plot of extracted liquid flow vs. extracted air flow was needed to determine when all the liquid film was extracted. Two samples are shown in Figure 4 for low and high water flows. For a certain inlet condition, the extracted liquid flow reaches a plateau beyond a certain value of the extracted air flow. The higher the inlet water flow, the greater percentage of the inlet air flow that needs to be extracted to reach the plateau. Once on the plateau it is assumed that the liquid film is extracted completely.

The amount of extracted gas was always the minimum necessary to remove the liquid film. Furthermore the pressure drop across the porous tube was minimized to minimize the gas extraction. This was achieved with a pore size of $100 \mu \mathrm{m}$ atter comparing measurements with $20 \mu \mathrm{m}, 40 \mu \mathrm{m}$ and $100 \mu \mathrm{m}$ porous tubes.

On the average the extracted gas was only $1.5 \%$ of the total gas flow. The worst case was only $10 \%$. Therefore the error induced by the gas extraction is generally small.

\subsection{Freon-113 experiment.}

in order to scale properly annular steam/water flow at high pressures and temperatures Freon has been shown to be one of the best fluids available. In Table 1 shows that it is possible to obtain the same density ratio as steam/water at 13.6 MPa using Freon-113 at $2 \mathrm{MPa}$.

A unique annular two-phase loop (Figure 5) using vapor/liquid Freon was designed and built to scale the steam/water conditions. Vapor is produced inside a steam generator $(20 \mathrm{kw})$ and is mixed with Freon liquid in the inlet of the test section to produce annular flow. The pressure of the steam generator is controlled automatically according to the set point established for the experiment. The first extraction unit works the same way as in the air/water loop. Additional precautions were taken to avoid condensation when the liquid is extracted. This liquid film goes to a flowmeter tank where the level can be read and the mass flow rate calculated. Two drain valves at the top of the flowmeter tank, with different discharge coefficients, were installed to 
control the optimal extraction point, i.e., when the plateau is reached. Thermocouples were installed before and along the test section to check that the data was obtained at steady-state saturated conditions. The range of the experiments were: $100<\rho_{g} j_{g}{ }^{2}<23000$ and $1.25<\rho_{f} j_{f}^{2}<325$ at 2.5 and 10 bar (Figure 6 ).

\section{Results}

Figure 7 shows a comparison of Ishii and Mishima's correlation (1989) and the four data sets: Cousins and Hewitt (1968), Keeys et. al. (1970), the present air/water data and the present Freon-113 data.

The dimensionless group $W e_{1}^{1.25} R e^{0.25}$ collapses all the data surprisingly well and it fits the data by Cousins and Hewitt very closely. This is not surprising since these data were use to obtain the correlation. Furthermore the correlation is in agreement with all the data for $\mathrm{We}_{1}{ }^{1.25} \mathrm{Re}_{1}{ }^{0.25}<10^{6}$. The scatter observed in the new data at values of $E$ below 0.1 is related to the uncertainty in the measurements and to the logarithmic scale which amplifies the effect. The same plot with a linear scale is shown in Figure 8 and, of course, the scatter is reduced in this region.

For $W e_{1}^{1.25} \mathrm{Re}_{1}{ }^{0.25}>10^{6}$ the correlation no longer fits the data. However the remarkable fact is that the low pressure air/water data, the high pressure steam/water data and the Freon-113 data are collapsed in this region. Nevertheless there is considerable scatter as shown in Figure 8 . The scatter of the air/water data set is systematic and depends on the liquid Reynolds number. There is an asymptotic lower limit to the film flow rate as the air flow is increased. This was observed because of the very high air flows that could be achieved in the experiment. This is not considered in Ishii and Mishima's correlation. Because of its significance, this phenomenon deserves to be studied separately and it will not be discussed any further at present.

The scatter in the Freon data is primarily due to condensation in the $100 \mathrm{p}$. It is impossible to eliminate all condensation and it is difficult to determine where it is taking place and to correct the data accordingly. Because the Freon loop has two extraction units we were able to develop a procedure to correct the data that works quite well but the reduction of this error is an on-going process. The scatter in the data of Keeys' et. al. is also considerable and we believe that it is related to condensation as well.
Figure 9 shows the comparison of the correlation by Dallman et. al. (1979) with all the data. The correlation fits all the air/water data well with $k_{A}=5.4$ $\times 10^{6} \mathrm{~s}^{2} / \mathrm{kg}$ and $W_{\mathrm{LFC}} / P=0.046 \mathrm{~kg} / \mathrm{ms}$. Although the scatter is appreciable, Dallman et al.'s correlation does account for an asymptotic lower limit to the film flow, so the scatter is more random compared to Ishii and Mishima's correlation. However the correlation does not match the Freon-113 data. Evidently the dimensional coefficients must be changed but it is not known how to do it at present.

\section{Conclusion}

The two new data sets that have been obtained are consistent with and extend previous entrainment data sets. Because the old data sets did not overlap it was not possible to find what dimensionless group collapses the entrainment data. However the new data sets provide plenty of overlap between low pressure air/water data and high pressure Freon113 data.

Therefore it is now possible to show that the dimensionless group proposed by ishii and Mishima (1989) scales data for a wide range of conditions, and in particular for high pressure steam/water flows. However the correlation by Ishii and Mishima

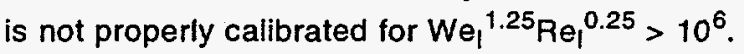
Furthermore it does not account for the asymptotic lower limit of the film flow rate observed at high gas flows. The new sets of data may be used to correct the correlation for these two effects.

\section{References}

Ishii, M. and Mishima, K., "Droplet entrainment correlation in annular two-phase flow", Int. J. Heat and Mass Transfer, Vol 32, n 10, pp 1835-1846, 1989.

Cousins, L. B. and Hewitt, G. F., "Liquid Phase Mass Transfer in Annular Two-Phase Flow: Droplet Deposition and Liquid Entrainment", UKAEA Report AERE-R5657, 1968.

Keeys, R. K. F., Ralph, J. C. and Roberts, D. N., "Liquid entrainment in adiabatic stream water flow at 500 and 1000 psi", AERE-R-6293.

Dallman, J. C., Jones, B. G., and Hanratty, T. J.,"Interpretation of Entrainment Measurements in Annular Gas-Liquid Flows", Two-Phase Momentum, Heat and Mass Transfer in Chemical, 
Process and Energy Engineering System, Vol. 2, 681-693, Hemisphere, Washington, D.C., 1979.

Wallis, G. B., "One Dimensional Two-Phase Flow", McGraw-Hill, 1969.

Kataoka, I. and Ishii, M. "Mechanism and correlation of droplet entrainment and deposition in annular two-phase flow," NUREG/CR 2885, ANL-82-44, 1982

\section{DISCLAIMER}

This report was prepared as an account of work sponsored by an agency of the United States Government. Neither the United States Government nor any agency thereof, nor any of their employees, makes any warranty, express or implied, or assumes any legal liability or responsibility for the accuracy, completeness, or usefulness of any information, apparatus, product, or process disclosed, or represents that its use would not infringe privately owned rights. Reference herein to any specific commercial product, process, or service by trade name, trademark, manufacturer, or otherwise does not necessarily constitute or imply its endorsement, recommendation, or favoring by the United States Government or any agency thereof. The views and opinions of authors expressed herein do not necessarily state or reflect those of the United States Government or any agency thereof. 


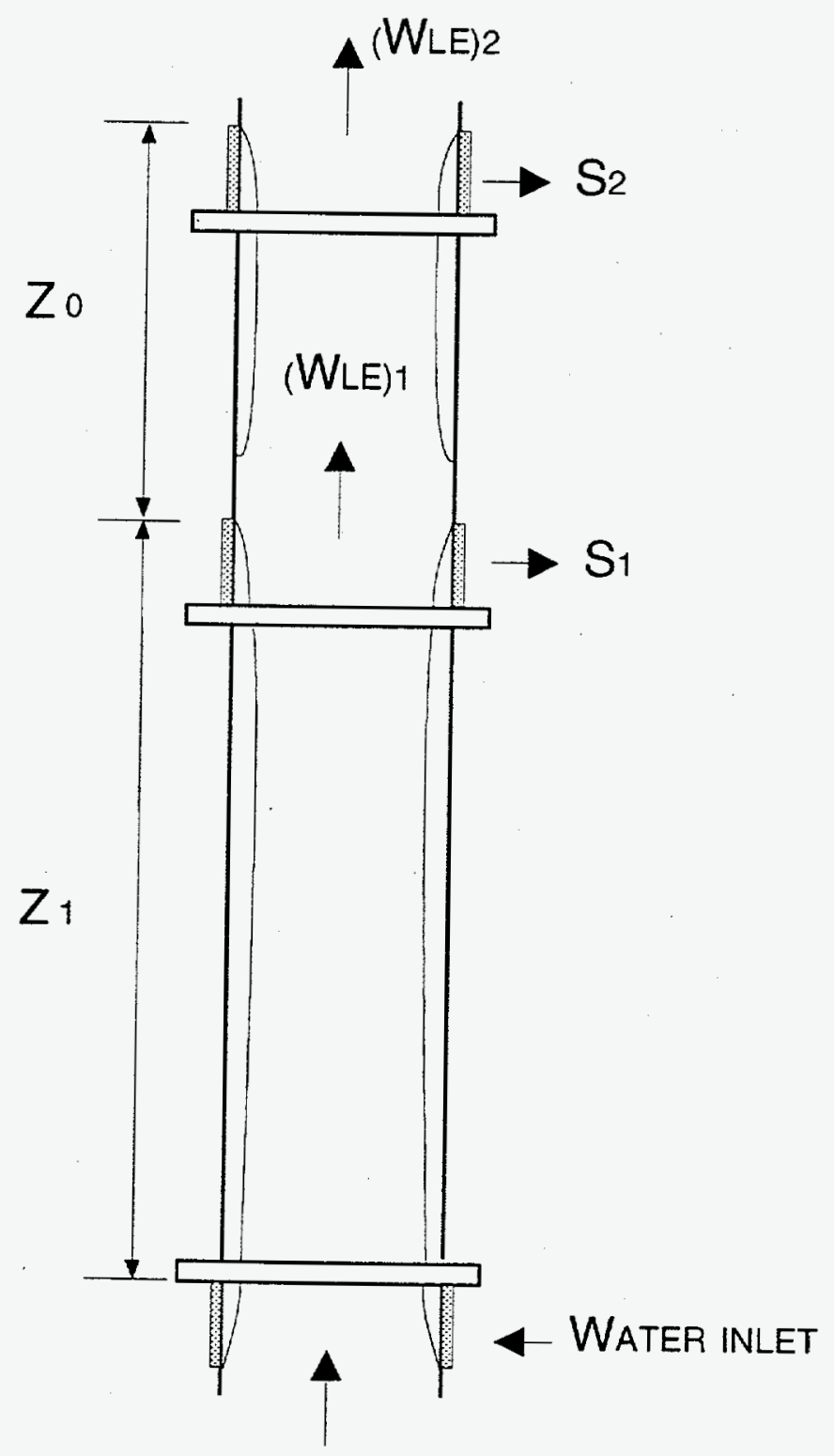

AIR INLET

Figure 1 Test section for Cousins and Hewitt's (1965) experiment. 


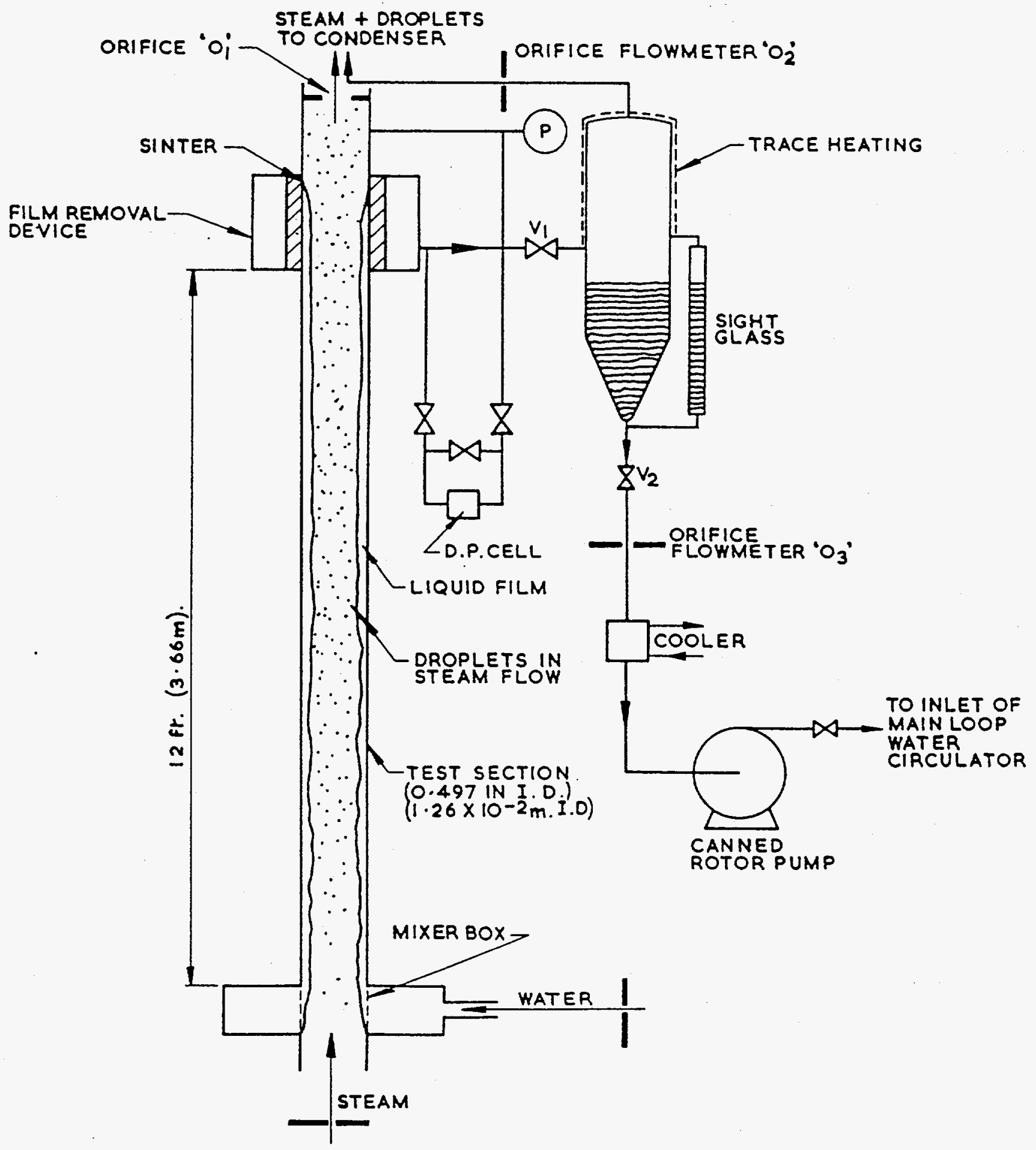

Figure 2 Test section for the experiment of Keeys et al. (1970) 




Figure 3 Flow regime map with air/water data. 


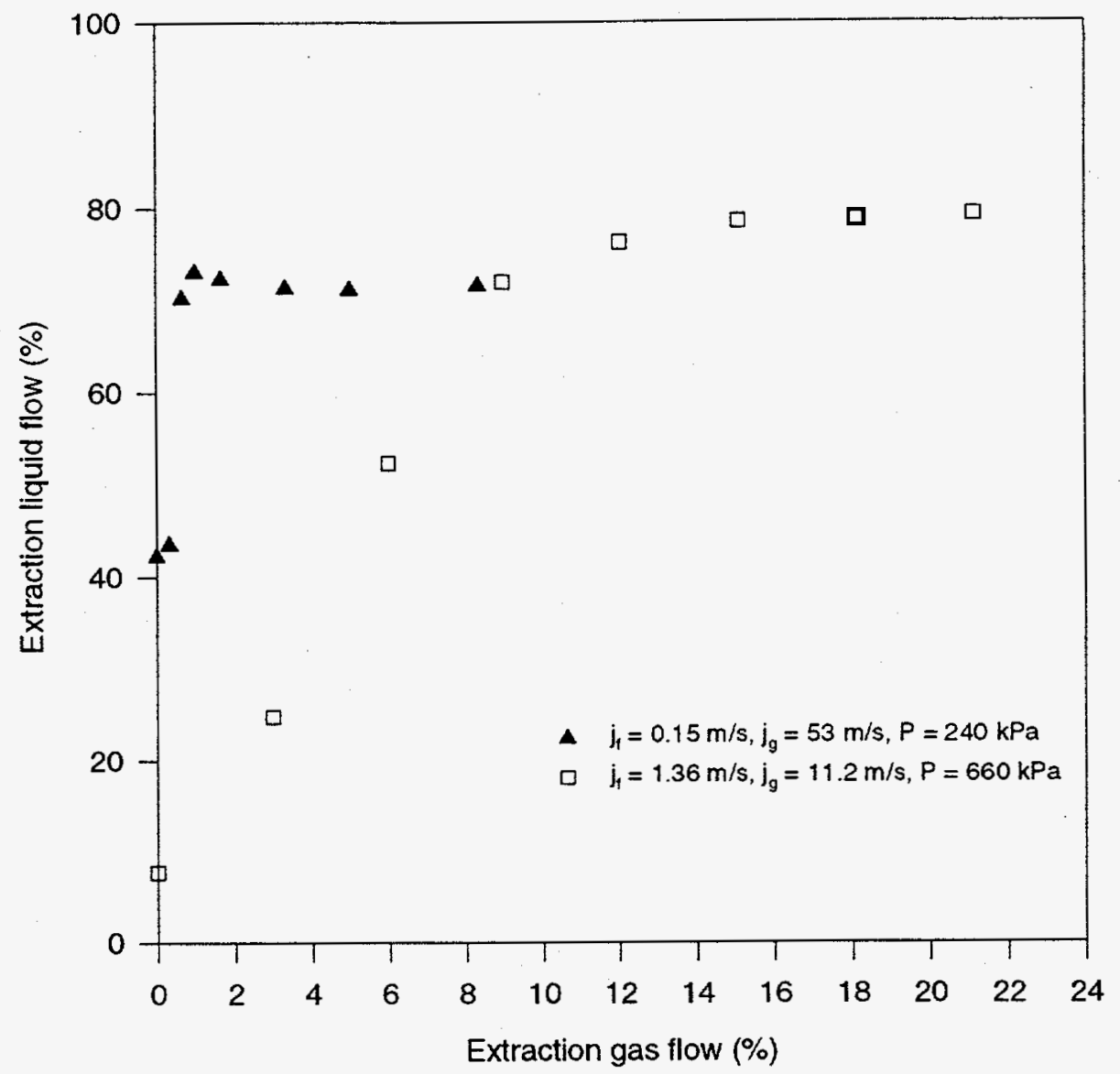

Figure 4 Extraction Liquid Flow vs. extraction gas flow. 


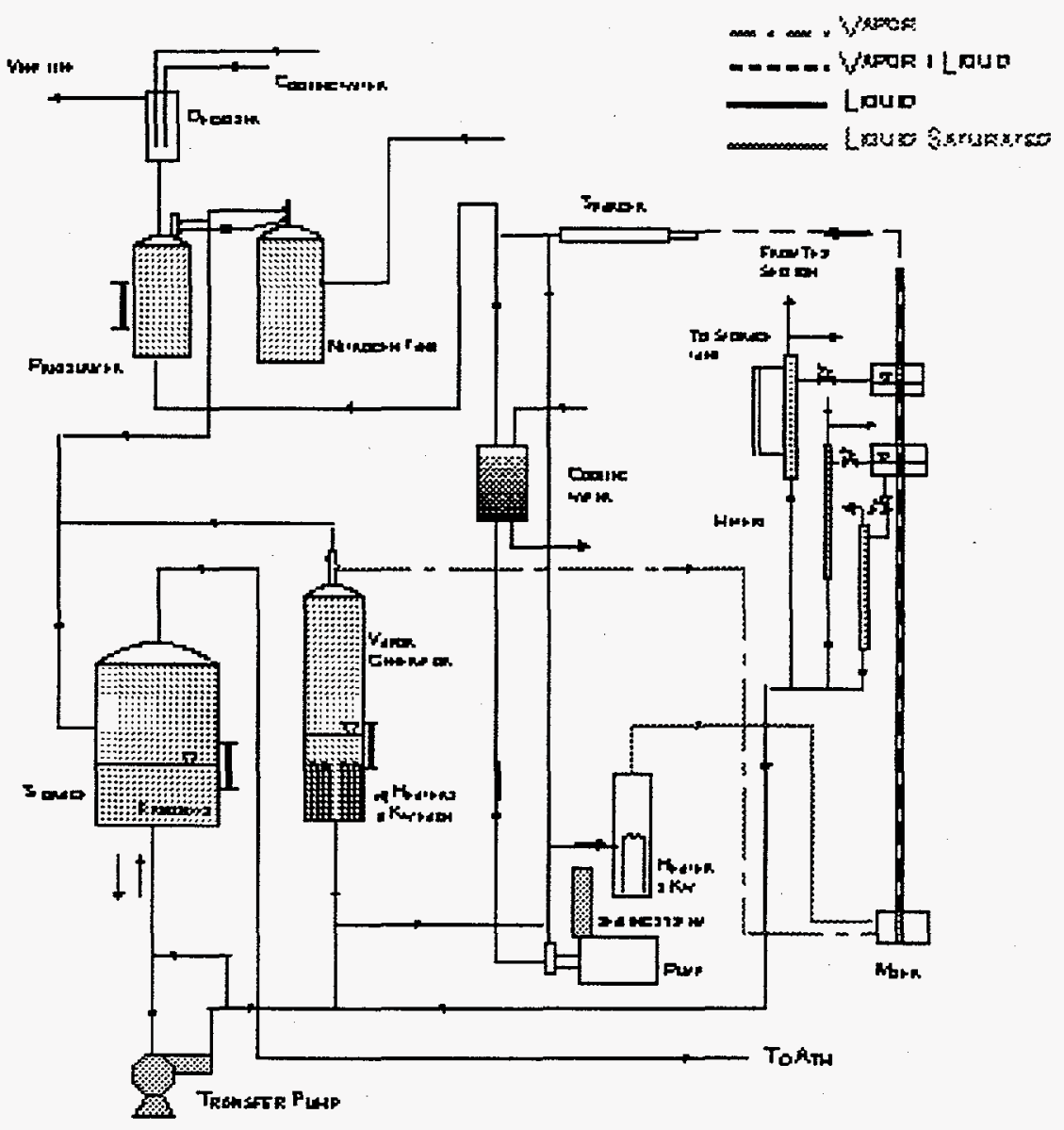

Figure 5 Vapor/liquid Freon-113 experimental loop. 


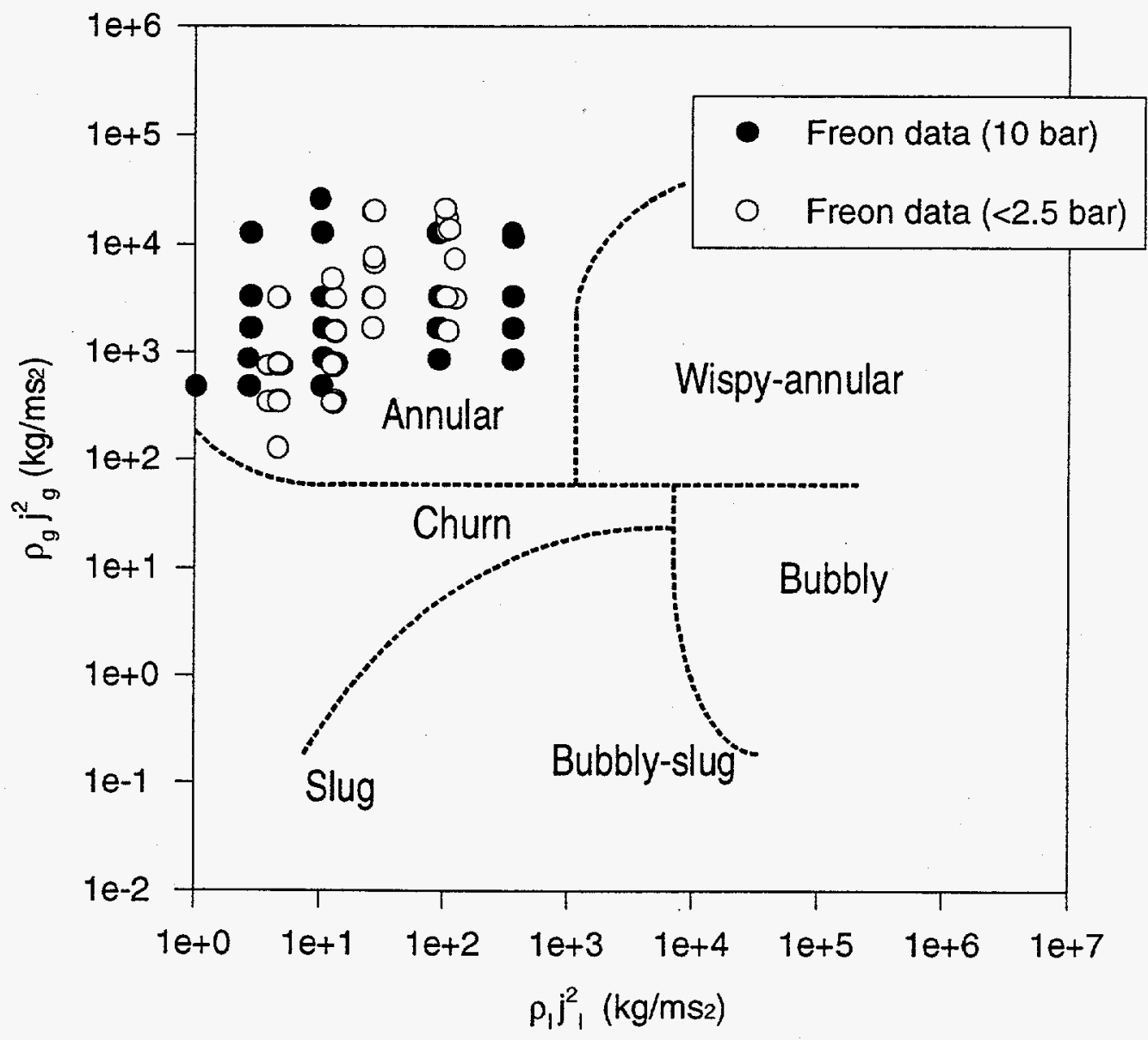

Figure 6 Flow regime map with vapor/liquid Freon-113 data. 




Figure 7 Comparison of Ishii and Mishima's correlation with data 


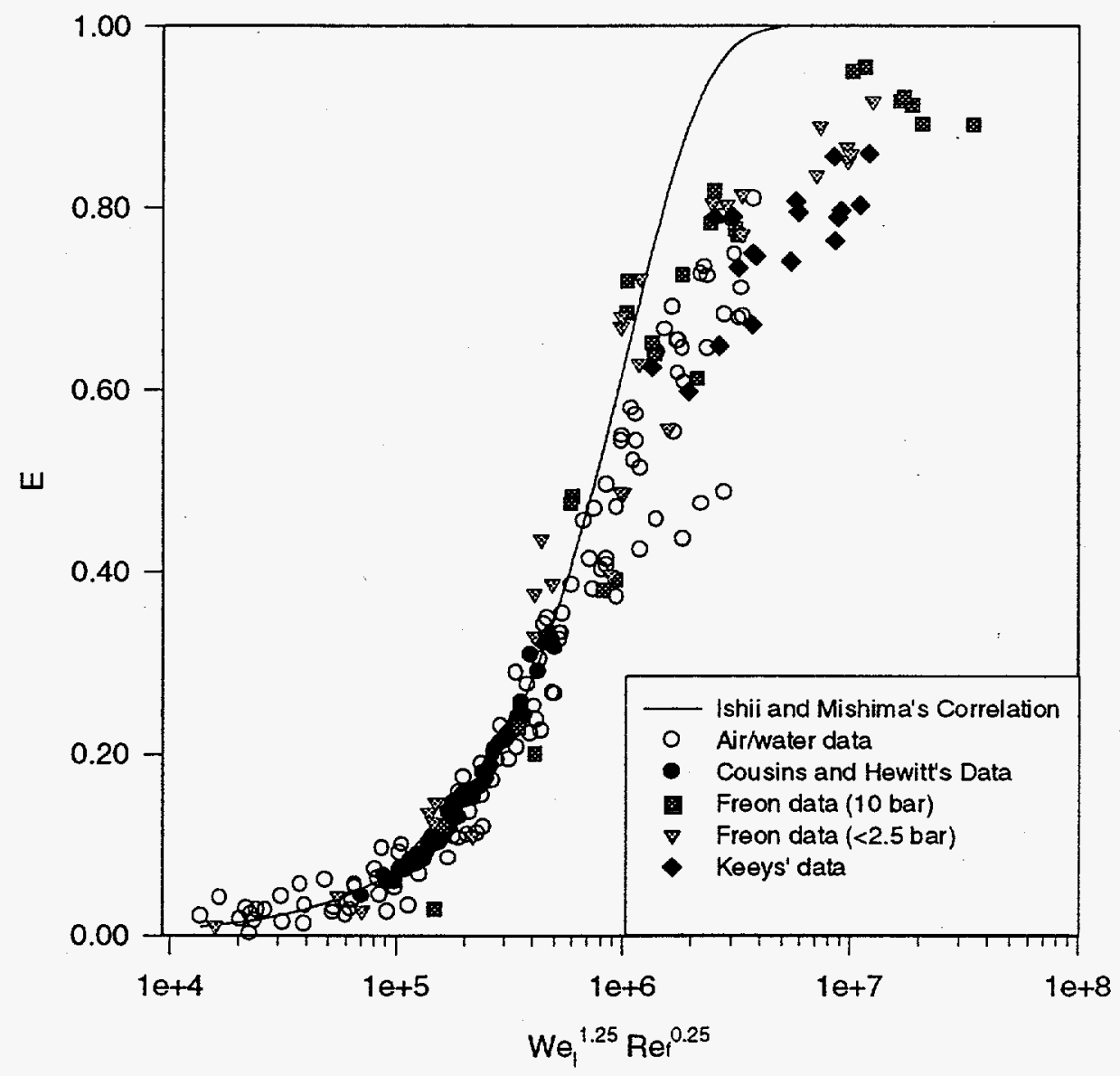

Figure 8 Comparison of Ishii and Mishima's correlation with data 


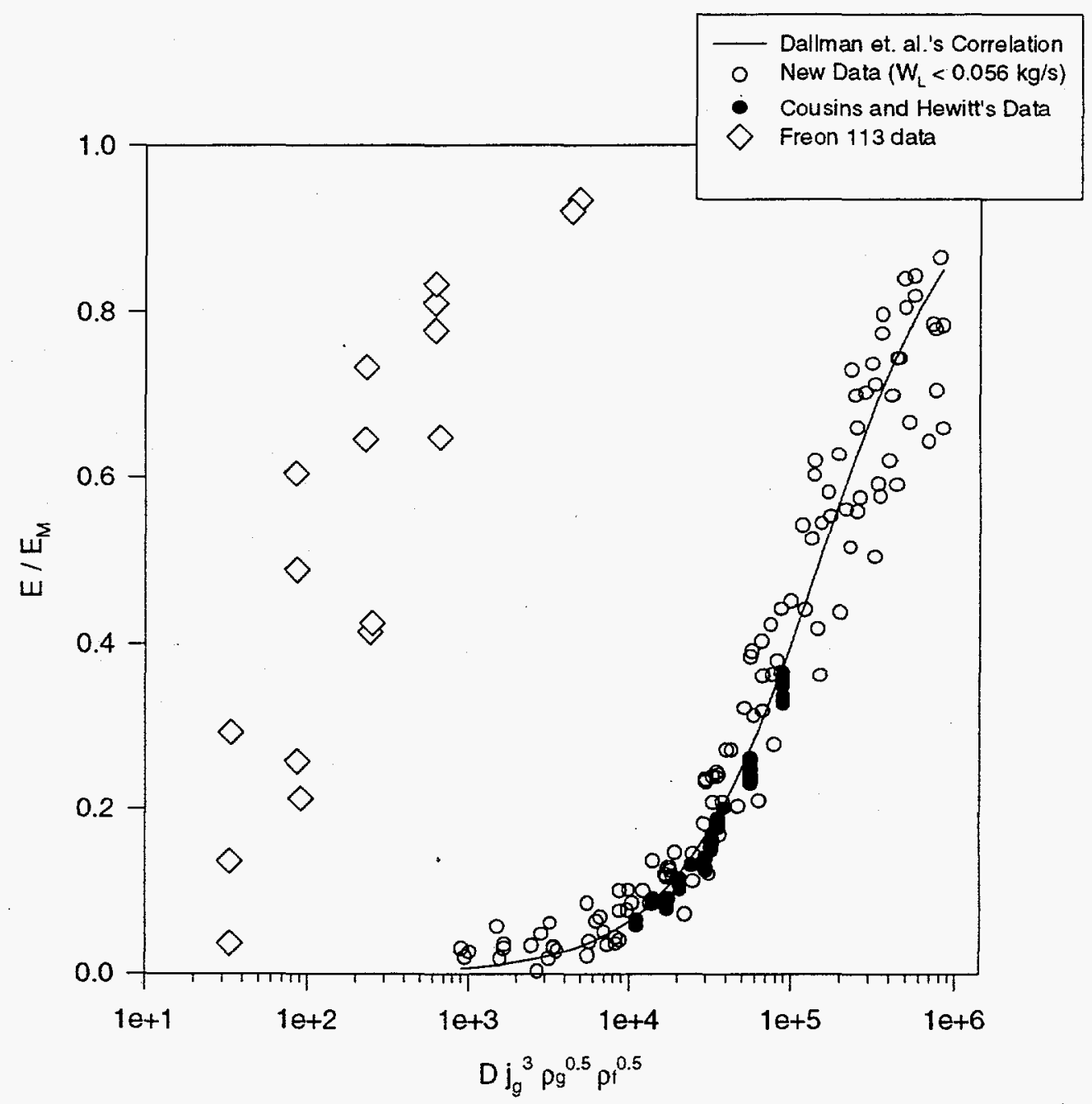

Figure 9 Comparison of Dallman et al. correlation with data 